\title{
Role and limitation of neoadjuvant hepatic arterial infusion chemotherapy in advanced hepatocelluar carcinoma patients with Child-Pugh class A
}

Beom-Hui Lee, Dong-Shik Lee, Chan Woo Cho and Sung-Su Yun*

\begin{abstract}
Background: Patients with advanced hepatocellular carcinoma (HCC) have a poor oncologic outcome. In this study, we evaluated the role and limitation of neoadjuvant hepatic arterial infusion chemotherapy (HAIC) in advanced HCC patients with Child-Pugh class A and the efficacy of liver resection subsequent to downstaging after neoadjuvant HAIC

Methods: In the present retrospective study, 103 patients with advanced HCC, who underwent neoadjuvant HAIC from April 2003 to March 2015 were analyzed. Response to HAIC was evaluated by dividing time period into after 3 cycles and after 6 cycles, each defined as early and late period. Liver resection after neoadjuvant HAIC was offered in patients who were considered as possible candidates for curative resection with tumor-free margin as well as sufficient future liver remnant volume.

Results: The median survival time (MST) in all patients was $14 \pm 1.7$ months. Response rate and disease control rate were 36.3\% (37) and 81.4\% (83) in early period, respectively, and 26.4\% (14) and 47.2\% (25), in late period,

respectively $(P=0.028)$. Twelve patients $(11.7 \%)$ underwent liver resection after neoadjuvant HAIC and the MST was $37 \pm 6.6$ months. One-, 3-, and 5-year recurrence-free survival after liver resection were 58.3\%, 36.5\%, and 24.3\% respectively. Liver resection was identified as the only independent prognostic factor that associated with overall survival in multivariate analysis ( $P=0.002)$

Conclusion: HAIC could be further alternative for the treatment of advanced HCC in patients with good liver function. If liver resection is possible after neoadjuvant HAIC, liver resection would provide better outcomes than HAIC alone.
\end{abstract}

Keywords: Hepatocellular carcinoma, Liver resection, Neoadjuvant hepatic arterial infusion chemotherapy

\section{Introduction}

There exist different opinions between surgeons and hepatologists in Eastern and Western countries, especially in the treatment of advanced hepatocellular carcinoma (HCC). Results of resection, transplantation, and systemic chemotherapy are not satisfactory, and recent trials of target therapies such as sorafenib and regorafenib in Western countries also are not so effective, despite initial expectations [1-4]. In patients with advanced HCC, the prognosis

\footnotetext{
* Correspondence: ssyun@med.yu.ac.kr

Department of Surgery, College of Medicine, Yeungnam University, 170 Hyeonchungno, Nam-gu, Daegu 42415, Republic of Korea
}

is extremely poor and median survival time (MST) is approximately $2.7-7$ months $[5,6]$.

We tried neoadjuvant hepatic arterial infusion chemotherapy (HAIC) in patients with advanced $\mathrm{HCC}$ and good liver function; most of the patients had multiple bilobar tumors and tumor(s) with main portal vein invasion.

We initiated HAIC based on the pharmacological benefits compared to that of intravenous injection. After intravenous injection, the chemotherapeutic drug reaches to the heart and only $5 \%$ of the cardiac output goes through the hepatic artery. Furthermore, most of the

(c) The Author(s). 2019 Open Access This article is distributed under the terms of the Creative Commons Attribution 4.0 International License (http://creativecommons.org/licenses/by/4.0/), which permits unrestricted use, distribution, and 
drugs lose more than $50 \%$ of their efficacy after 1 cycle of systemic circulation [7-10]. On the other hand, HAIC is more effective than intravenous chemotherapy because of its first-pass metabolism and topical accumulation of chemotherapeutic agents in the liver [7, 11, 12]. Fortunately, it is already demonstrated that HAIC in patients with advanced HCC resulted in the favorable response rate (RR) and survival benefits $[5,9,13,14]$.

In this study, we evaluated the role and limitation of neoadjuvant HAIC in advanced HCC patients with Child-Pugh class A and the efficacy of liver resection subsequent to downstaging after HAIC.

\section{Methods}

\section{Patients}

From April 2003 to March 2015, 136 patients with advanced HCC underwent neoadjuvant HAIC at our institution. HAIC was performed in preserved functional liver reserved with Child-Pugh class $\mathrm{A}$ and in patients with advanced HCC according to the Barcelona Clinic Liver Cancer guideline. In this retrospective study, patients with serious comorbidities such as cardiopulmonary insufficiency or other medical condition, or concurrent malignant tumor were excluded. Patients who did not undergo more than 3 cycles of HAIC were also excluded. After exclusion, a total of 103 patients was analyzed in this study. This study was approved by the Institutional Review Board of Yeungnam University Medical Center, Daegu, Republic of Korea (IRB no. 2018-12-016-001).

\section{Treatment protocol}

HAIC was performed via a port system inserted through a femoral artery in a subcutaneous pocket in the right thigh. The patients were treated with 5-fluorouracil (5FU, JW Pharmaceutical, Seoul, Korea, $750 \mathrm{mg} / \mathrm{m}^{2}$ ) for 2 $\mathrm{h}$ and cisplatin (JW Pharmaceutical, Seoul, Korea, 25 $\mathrm{mg} / \mathrm{m}^{2}$ ) for $1 \mathrm{~h}$ from day 1 to 4 . Chemotherapeutic agents were repeatedly administrated every 4 weeks after evaluating the adverse effects of HAIC. Intravenous hydration with antiemetic treatment was performed before and after cisplatin infusion to prevent cisplatin-induced nephrotoxicity.

The response to HAIC was evaluated after 3 and $6 \mathrm{cy}$ cles. The early period response was defined as after $3 \mathrm{cy}-$ cles of HAIC, and the late period response was defined as after 6 cycles of HAIC. The tumor response was evaluated by contrast-enhanced computed tomography and tumor marker after every 3 cycles of HAIC. Radiologic response to treatment was assessed by Modified Response Evaluation Criteria in solid tumors and classified as complete response $(\mathrm{CR})$, partial response $(\mathrm{PR})$, stable disease (SD), or progressive disease (PD). The response was defined as the achievement of $\mathrm{CR}$ or $\mathrm{PR}$ and the disease control was defined as the achievement of CR, $\mathrm{PR}$, or SD. To evaluate biologic tumor response, the alterations in alpha-fetoprotein (AFP) were analyzed based on initial AFP value and AFP value after treatment.

The operability was assessed through multidisciplinary discussions with hepatobiliary surgeon, hepatologist, and radiologist. Liver resection was offered to patients who were considered as the candidates for curative resection with tumor-free margin as well as sufficient future liver remnant volume.

\section{Statistical analysis}

Continuous variables were expressed as mean with standard deviation. Categorical variables were calculated using the chi-square test and Fisher's exact test. Survival was calculated using the Kaplan-Meier method, and differences between the groups were compared using the log-rank test. Variables associated with survival were evaluated by univariate and multivariate analyses using a Cox proportional hazard model. All statistical analyses were performed using statistical software IBM SPSS version 21.0 (IBM Co., Armonk, NY, USA). Statistical significance was defined as a $P$ value of less than 0.05 .

\section{Results}

\section{Baseline characteristics of the patients}

The baseline characteristics of the patients are summarized in Table 1 . The mean age of the patients was 53.7 \pm 9.0 years and 93 patients $(90.7 \%)$ were male. The most common etiology for $\mathrm{HCC}$ was hepatitis B virus (77.7\%) and the second was alcohol (7.7\%). The number of patients with bilobar HCC or portal vein tumor thrombus (PVTT) was 59 (57.3\%) and 69 (67.0\%) respectively. Extrahepatic metastasis was identified in $20(19.4 \%)$ patients at the time of enrollment, and lung or lymph nodes were predominant.

\section{Comparison of response to HAIC between the early and late period}

MST in the patients treated with HAIC was $14 \pm 1.7$ months. Patients who obtained CR, PR, SD, and PD were 2 (2.0\%), 35 (34.3\%), 46 (45.1\%), and 19 (18.6\%) in early period, respectively, and 5 (9.4\%), 9 (17.0\%), $11(20.8 \%)$, and $28(52.8 \%)$ in late period, respectively. In the early period, $\mathrm{RR}$ and disease control rate (DCR) were $36.3 \%$ (37) and $81.4 \%$ (83), respectively. RR and DCR in the late period were $26.4 \%$ (14) and $47.2 \%$ (25), respectively. RR in the early period to HAIC was significantly better compared to the late period $(P=0.028$, Table 2$)$. 
Table 1 Baseline characteristics of patients treated with HAIC for advanced hepatocellular carcinoma

\begin{tabular}{|c|c|}
\hline Characteristic & \\
\hline Mean age (years) & $53.7 \pm 9.0$ \\
\hline Gender, male & $93(90.3 \%)$ \\
\hline \multicolumn{2}{|l|}{ Etiology } \\
\hline HBV & $80(77.7 \%)$ \\
\hline $\mathrm{HCV}$ & $4(3.9 \%)$ \\
\hline Alcohol & $8(7.7 \%)$ \\
\hline Others & $11(10.7 \%)$ \\
\hline \multicolumn{2}{|l|}{ Preoperative laboratory test } \\
\hline Total bilirubin (mg/dL) & $1.1 \pm 0.6$ \\
\hline PT (\%) & $92.7 \pm 16.0$ \\
\hline Albumin (g/dL) & $3.9 \pm 0.5$ \\
\hline Platelet count $\left(\times 10^{3} / \mu \mathrm{L}\right)$ & $184.5 \pm 89.4$ \\
\hline $\operatorname{AFP}(\mathrm{ng} / \mathrm{mL})$ & $10587.7 \pm 25449.0$ \\
\hline PIVKA-II (mAU/mL) & $7386.3 \pm 19924.9$ \\
\hline Tumor size (mm) & $70.9 \pm 39.8$ \\
\hline \multicolumn{2}{|l|}{ Tumor number } \\
\hline Single & $19(18.4 \%)$ \\
\hline Multiple & $84(81.6 \%)$ \\
\hline Bilobar HCC & $59(57.3 \%)$ \\
\hline PVTT & $69(67.0 \%)$ \\
\hline Extrahepatic metastasis & $20(19.4 \%)$ \\
\hline Lung & $8(7.7 \%)$ \\
\hline Lymph node & $9(8.7 \%)$ \\
\hline Lung and lymph node & $1(1.0 \%)$ \\
\hline Bone & $1(1.0 \%)$ \\
\hline Adrenal gland & $1(1.0 \%)$ \\
\hline HAIC cycle & $5.7 \pm 2.3$ \\
\hline Previous locoregional treatment & $35(34.0 \%)$ \\
\hline
\end{tabular}

HAIC hepatic arterial infusion chemotherapy, SD standard deviation, $H B V$ hepatitis B, HCV hepatitis C, PT prothrombin time, AFP alpha-fetoprotein, PIVKA-Il proteins induced by vitamin $\mathrm{K}$ antagonist-II, HCC hepatocellular carcinoma, PVTT portal vein tumor thrombus

\section{Liver resection subsequent to downstaging after neoadjuvant HAIC}

Twelve (11.7\%) patients underwent liver resection after neoadjuvant HAIC. In liver resection after neoadjuvant HAIC group, MST and overall survival (OS) were significantly better compared to HAIC alone group (MST $37 \pm 6.6$ vs. $13 \pm 1.4$ months, $P=0.002$, Fig. 1a). One-, 3 -, and 5-year recurrence-free survival (RFS) were 58.3\%, $36.5 \%$, and $24.3 \%$ respectively (Fig. 1 b). The median time to recurrence was $13 \pm 7.4$ months. Five patients had bilobar HCC, 10 patients had PVTT, and 1 patient had both bilobar HCC and PVTT. Extrahepatic metastasis was found in 1 patient and identified as paraaortic lymph node metastasis, and complete remission of the
Table 2 Comparison of response between the early and late period response

\begin{tabular}{|c|c|c|c|}
\hline Response & $\begin{array}{l}\text { Early period } \\
\text { (after } 3 \text { cycles) }\end{array}$ & $\begin{array}{l}\text { Late period } \\
\text { (after } 6 \text { cycles) }\end{array}$ & $P$ value \\
\hline$\overline{C R}$ & $2(2.0 \%)$ & $5(9.4 \%)$ & \\
\hline$P R$ & $35(34.3 \%)$ & $9(17.0 \%)$ & \\
\hline SD & $46(45.1 \%)$ & $11(20.8 \%)$ & \\
\hline PD & $19(18.6 \%)$ & $28(52.8 \%)$ & \\
\hline $\mathrm{RR}(\mathrm{CR}+\mathrm{PR})$ & 37 (36.3\%) & $14(26.4 \%)$ & 0.028 \\
\hline $\mathrm{DCR}(\mathrm{CR}+\mathrm{PR}+\mathrm{SD})$ & $83(81.4 \%)$ & $25(47.2 \%)$ & 0.492 \\
\hline
\end{tabular}

metastatic lesion after HAIC was recognized. Tumor size reduction and PVTT regression were the main causes of liver resection. The recurrence was identified in $10 \mathrm{pa}-$ tients, and intrahepatic recurrence in 7 patients, systemic recurrence in 2 patients, and both in 1 patient. Details of the patients were summarized in Table 3.

\section{Prognostic factors associated with overall survival of HAIC} In univariate analysis, OS was associated with total bilirubin level and liver resection. While liver resection was the only independent prognostic factor to be associated with OS in multivariate analysis (hazard ratio, 3.480; 95\% confidence interval, $1.587-7.630 ; P=0.002$, Table 4).

\section{Discussion}

There are a few remaining treatment options for patients with advanced HCC. Sorafenib is regarded as the first line therapy for advanced $\mathrm{HCC}$ according to BCLC guideline and other molecular target agents such as lenvatinib or regorafenib are considered as effective alternatives [3]. However, MST and RR in patients who treated with sorafenib is unsatisfactory (10.7 months and 2 to $3.3 \%$, respectively) $[4,15]$. In REFLECT trial, the efficacy of lenvatinib exhibited a limitation because patients with major PVTT and with more than $50 \%$ of liver involvement were excluded [3]. In this regard, HAIC is considered as an effective alternative with better $R R$ than sorafenib. There exist a number of studies associated with HAIC in East Asia stating MST and RR in patients treated with HAIC as 6.5 to 14 months and 24 to $52 \%$, respectively [7, 8, 16-18]. In our study, MST and RR were $14 \pm 1.7$ months and $26.4 \%$, respectively, with values consistent with previous studies.

Liver resection for advanced $\mathrm{HCC}$ is still controversial because of high surgical risk, poor prognosis, and difficulty in judging operability although several studies have shown a survival benefit in intermediate or advanced HCC [19-24]. On the contrary, downstaging after 

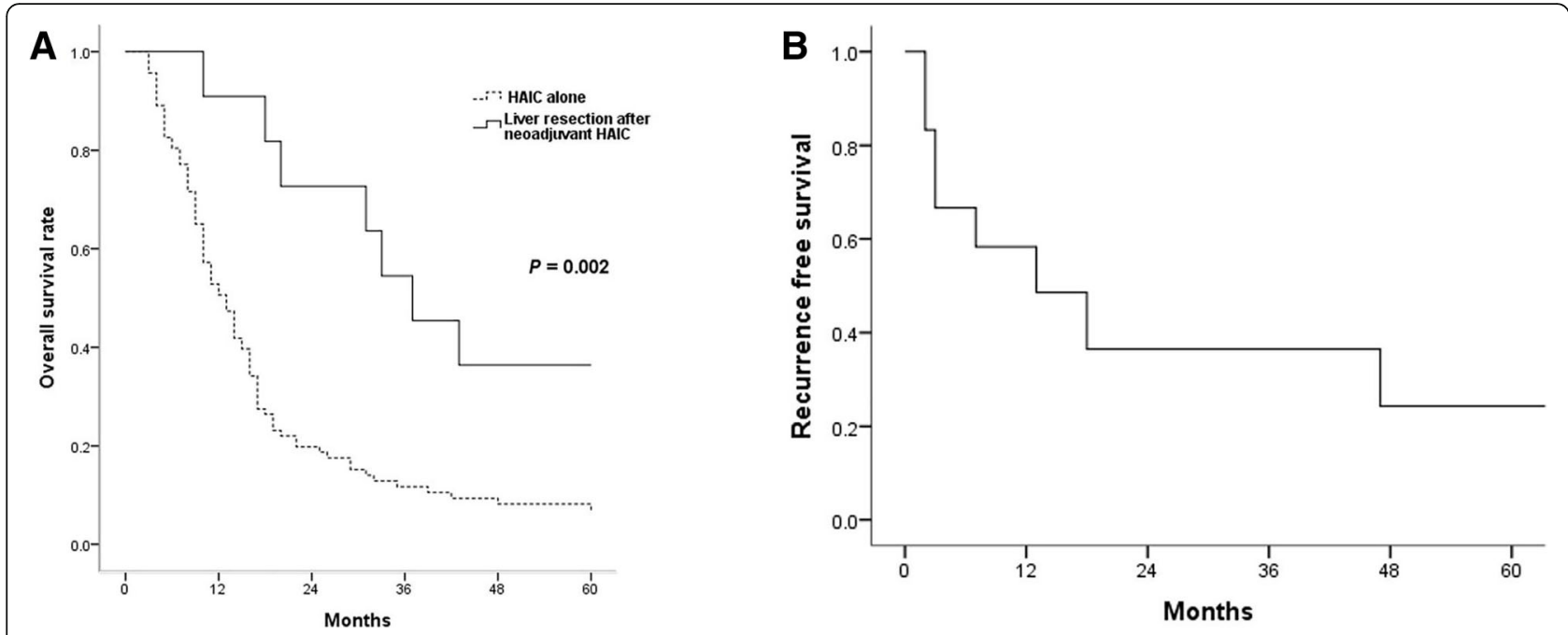

Fig. 1 a Overall survival between liver resection after neoadjuvant HAIC and HAIC alone group. b Recurrence-free survival rate in liver resection after neoadjuvant HAIC group. HAIC hepatic arterial infusion chemotherapy

neoadjuvant HAIC provides an opportunity for the patients who undergo liver resection to obtain better survival outcomes. In our study, 12 patients (11.7\%) who underwent liver resection after neoadjuvant HAIC had better OS than patients who underwent HAIC alone. One patient had a postoperative complication of grade III or higher because of postoperative bleeding. However, there were no postoperative morbidity and mortality associated with poor liver function. Several studies have reported survival benefits of liver resection after downstaging using neoadjuvant HAIC or HAIC with radiotherapy $[16,25,26]$ and exhibited similar results. Considering these acceptable results, liver resection subsequent to downstaging after neoadjuvant treatment can be regarded as one of the treatment options for patients with advanced $\mathrm{HCC}$ and with good liver function. To obtain downstaging of HCC, it is necessary to know whether there is a response to treatment or not as early as possible. In our study, radiologic findings and tumor marker were used for evaluation of response to HAIC after every 3 cycles. In addition, the alteration in AFP level was used for early assessment of response so that we could predict tumor burden and biology. In early period, RR was significantly better than compared to late period ( $36.3 \%$ vs. $26.4 \%, P=0.028)$. It was considered that the resistance to HAIC was caused by repeated HAIC. Thus, in patients with both a radiologic response and decreased or normalized tumor markers in the early

Table 3 Profiles of patients who underwent liver resection after neoadjuvant HAIC

\begin{tabular}{llllllllllll}
\hline Case & Gender/age & Etiology & HAIC cycle & $\begin{array}{l}\text { AFP (initial- } \\
\text { preoperative) }\end{array}$ & $\begin{array}{l}\text { Bilobar } \\
\text { HCC }\end{array}$ & $\begin{array}{l}\text { PVTT } \\
\text { Extrahepatic } \\
\text { metastasis }\end{array}$ & $\begin{array}{l}\text { Resection } \\
\text { Margin }\end{array}$ & $\begin{array}{l}\text { Recurrence } \\
\text { (time/site) } \\
\text { (months) }\end{array}$ & $\begin{array}{l}\text { Survival time } \\
\text { (months) }\end{array}$ \\
\hline 1 & F/73 & HBV & 6 & $3170-99.4$ & No & Yes & Yes (LNs) & Minor & Tumor-free & No & 81 \\
2 & M/44 & HBV & 6 & $5845-2.8$ & No & Yes & No & Major & Tumor-free & No & 120 \\
3 & M/61 & HBV & 8 & $11.74-8.8$ & No & Yes & No & Major & Tumor-free & $18 /$ lung & 46 \\
4 & M/40 & HBV & 4 & $158.0-432.2$ & No & Yes & No & Major & Tumor-free & $2 /$ liver & 18 \\
5 & M/42 & HBV & 6 & $950-60.2$ & No & Yes & No & Major & Tumor-free & $13 /$ lung & 31 \\
6 & M/53 & HBV & 4 & $369.9-337.7$ & No & Yes & No & Major & Tumor-free & $2 /$ liver & 10 \\
7 & F/48 & HBV & 6 & $188663-40762$ & Yes & No & No & Minor & Tumor-free & $3 /$ liver & 37 \\
8 & M/44 & HBV & 7 & $7.5-6.7$ & Yes & Yes & No & Minor & Tumor-free & $10 /$ liver & 33 \\
9 & M/56 & HBV & 3 & $911.6-23.1$ & No & Yes & No & Major & Tumor-free & $47 /$ liver & 68 \\
10 & M/47 & HBV & 6 & $1038-701.1$ & Yes & No & No & Major & Tumor-free & $13 /$ liver, lung 43 \\
11 & F/39 & HBV & 8 & $121000-6047$ & Yes & Yes & No & Major & Tumor-involved & $7 /$ liver & 20 \\
12 & M/46 & HBV & 6 & $188.6-17.2$ & Yes & Yes & No & Minor & Tumor-free & $3 /$ liver & 67 \\
\hline
\end{tabular}

HAIC hepatic arterial infusion chemotherapy, HBV hepatitis B, AFP alpha-fetoprotein, HCC hepatocellular carcinoma, PVTT portal vein tumor thrombus, LN lymph node 
Table 4 Prognostic factors associated with overall survival of HAIC

\begin{tabular}{|c|c|c|c|}
\hline \multirow[t]{2}{*}{ Risk factors } & \multirow{2}{*}{$\begin{array}{l}\text { Univariate } \\
P \text { value }\end{array}$} & \multicolumn{2}{|l|}{ Multivariate } \\
\hline & & $\overline{\mathrm{HR}}(95 \% \mathrm{Cl})$ & $P$ value \\
\hline Age (years) & 0.123 & & \\
\hline Gender & 0.870 & & \\
\hline Total bilirubin (mg/dL) & 0.033 & $1.312(0.943-1.825)$ & 0.108 \\
\hline Platelet $\left(\times 10^{3} / \mathrm{mL}\right)$ & 0.342 & & \\
\hline Albumin (g/dL) & 0.556 & & \\
\hline PT (\%) & 0.153 & & \\
\hline AFP $(\mathrm{ng} / \mathrm{mL})$ & 0.446 & & \\
\hline PIVKA-II (m AU/mL) & 0.205 & & \\
\hline Tumor size & 0.446 & & \\
\hline Tumor number & 0.105 & & \\
\hline $\begin{array}{l}\text { Previous locoregional } \\
\text { treatment }\end{array}$ & 0.528 & & \\
\hline PVIT & 0.407 & & \\
\hline Extrahepatic metastasis & 0.595 & & \\
\hline HAIC cycle & 0.119 & & \\
\hline Liver resection after HAIC & 0.001 & $3.480(1.587-7.630)$ & 0.002 \\
\hline
\end{tabular}

HAIC hepatic arterial infusion chemotherapy, $H R$ hazard ratio, $\mathrm{Cl}$, confidence interval, $P T$ prothrombin time, AFP alpha-fetoprotein, PIVKA-Il proteins induced by vitamin $\mathrm{K}$ antagonist-II, PVTT portal vein tumor thrombus, ORR objective response rate

period, we recommend repeat evaluation resectability as early as possible. And if possible, liver resection should be considered to obtain survival benefits before progression of HCC or resistance to HAIC. On the contrary, in case of increase in AFP value during the treatment, precise evaluation of response to HAIC should be carried out. And if resistance to HAIC is predicted, switching to other treatments should be considered at an early period.

In several studies, 1- and 5-year RFS after hepatectomy in HCC patients were reported to range from 65 to $72 \%$ and from 30 to $39 \%$, respectively. The median time to recurrence was 22 to 34 months [27, 28]. Although our study showed worse outcomes than previous studies, we hypothesize that our results could be acceptable while considering the fact that we analyzed patients with advanced $\mathrm{HCC}$ subsequent to downstaging after neoadjuvant HAIC.

In this study, patients with extrahepatic metastasis were included. Although HAIC with focus on intrahepatic lesions and extrahepatic metastasis has not responded well, intrahepatic lesions were considered as a significant prognostic factor in survival rather than extrahepatic metastasis in previous studies [7, $29,30]$. In the present study, extrahepatic metastasis was not identified as a significant factor in OS. Thus, it is proposed that the use of HAIC could be considered in patients with extrahepatic metastasis.
One of the limitations of this study was that there was no consensus for the standard treatment protocol of HAIC. A number of studies have reported various treatment regimen for HAIC. Most commonly used regimens are 5-fluorouracil with low-dose cisplatin (FP), and others are cisplatin alone, high-dose FP, FP plus interferon, FP plus leucovorin and FP plus epirubicin [3, 7-9, 13, 14, 31]. We designed a treatment protocol using low-dose FP. However, the optimal regimen for HAIC still remains a controversial issue. In addition, the included data from a single institution were retrospectively analyzed; hence, we could not completely exclude the selection-bias and could not obtain a sufficient number of cases. Apparently, though it is difficult to conduct randomized controlled trials for HAIC because of ethical issues, further investigations for optimization of HAIC protocol and a large-scale multicenter study are needed.

\section{Conclusion}

HAIC could be another alternative for the treatment of advanced HCC in patients with good liver function. If liver resection is possible after neoadjuvant HAIC, liver resection would provide better outcomes than HAIC alone.

\begin{abstract}
Abbreviations
AFP: Alpha-fetoprotein; CR: Complete response; DCR: Disease control rate; FP: 5-fluorouracil with cisplatin; HAIC: Hepatic arterial infusion chemotherapy; HCC: Hepatocellular carcinoma; MST: Median survival time; OS: Overall survival; PD: Progressive disease; PR: Partial response; PVTT: Portal vein tumor thrombus; RFS: Recurrence-free survival; RR: Response rate; SD: Stable disease
\end{abstract}

\section{Acknowledgements}

Not applicable.

\section{Authors' contributions}

$\mathrm{BHL}$ and SSY planned and designed the study. BHL collected the data. BHL, CWC, and DSL analyzed and interpreted the patient data. CWC, DSL, and SSY commented on drafts of the paper. BHL was a major contributor in writing the manuscript. All authors read and approved the final manuscript.

Funding

The authors declare that they have no funding.

\section{Availability of data and materials}

The anonymized data used and/or analyzed during the current study are available from the corresponding author on reasonable request.

Ethics approval and consent to participate

This study was approved by the Institutional Review Board of Yeungnam University Medical Center, Daegu, Republic of Korea (IRB no. 2018-12-016-001).

\section{Consent for publication}

Not applicable

Competing interests

The authors declare that they have no competing interests. 
Received: 28 May 2019 Accepted: 6 August 2019

Published online: 15 August 2019

\section{References}

1. Kudo M. Treatment of advanced hepatocellular carcinoma with emphasis on hepatic arterial infusion chemotherapy and molecular targeted therapy Liver Cancer. 2012;1(2):62-70.

2. Colagrande S, Inghilesi AL, Aburas S, Taliani GG, Nardi C, Marra F. Challenges of advanced hepatocellular carcinoma. World J Gastroenterol. 2016;22(34): 7645-59.

3. Ikeda M, Morizane C, Ueno M, Okusaka T, Ishii H, Furuse J. Chemotherapy for hepatocellular carcinoma: current status and future perspectives. Jpn J Clin Oncol. 2018;48(2):103-14.

4. Llovet JM, Ricci S, Mazzaferro V, Hilgard P, Gane E, Blanc JF, et al. Sorafenib in advanced hepatocellular carcinoma. N Engl J Med. 2008;359(4):378-90.

5. Minagawa M, Makuuchi M. Treatment of hepatocellular carcinoma accompanied by portal vein tumor thrombus. World J Gastroenterol. 2006 12(47):7561-7.

6. Obi S, Sato S, Kawai T. Current status of hepatic arterial infusion chemotherapy. Liver Cancer. 2015;4(3):188-99.

7. Song DS, Bae SH, Song MJ, Lee SW, Kim HY, Lee YJ, et al. Hepatic arterial infusion chemotherapy in hepatocellular carcinoma with portal vein tumor thrombosis. World J Gastroenterol. 2013;19(29):4679-88.

8. Saeki I, Yamasaki T, Maeda M, Hisanaga T, Iwamoto T, Fujisawa K, et al. Treatment strategies for advanced hepatocellular carcinoma: sorafenib vs hepatic arterial infusion chemotherapy. World J Hepatol. 2018;10(9):571-84.

9. Park JY, Ahn SH, Yoon YJ, Kim JK, Lee HW, Lee DY, et al. Repetitive shortcourse hepatic arterial infusion chemotherapy with high-dose 5-fluorouracil and cisplatin in patients with advanced hepatocellular carcinoma. Cancer. 2007;110(1):129-37.

10. Ueda H, Fukuchi H, Tanaka C. Toxicity and efficacy of hepatic arterial infusion chemotherapy for advanced hepatocellular carcinoma (Review). Oncol Lett. 2012;3(2):259-63.

11. Ensminger WD, Rosowsky A, Raso V, Levin DC, Glode M, Come S, et al. A clinical-pharmacological evaluation of hepatic arterial infusions of 5-fluoro2'-deoxyuridine and 5-fluorouracil. Cancer Res. 1978;38(11 Pt 1):3784-92.

12. Kemeny N, Fata F. Hepatic-arterial chemotherapy. Lancet Oncol. 2001;2(7): $418-28$

13. Kodama K, Kawaoka T, Aikata H, Uchikawa S, Nishida Y, Inagaki Y, et al. Comparison of outcome of hepatic arterial infusion chemotherapy combined with radiotherapy and sorafenib for advanced hepatocellular carcinoma patients with major portal vein tumor thrombosis. Oncology. 2018:94(4):215-22

14. Miyaki D, Aikata H, Honda $Y$, Naeshiro N, Nakahara T, Tanaka M, et al. Hepatic arterial infusion chemotherapy for advanced hepatocellular carcinoma according to Child-Pugh classification. J Gastroenterol Hepatol. 2012;27(12):1850-7.

15. Cheng A-L, Kang Y-K, Chen Z, Tsao C-J, Qin S, Kim JS, et al. Efficacy and safety of sorafenib in patients in the Asia-Pacific region with advanced hepatocellular carcinoma: a phase III randomised, double-blind, placebocontrolled trial. The Lancet Oncology. 2009;10(1):25-34.

16. Hamaoka M, Kobayashi T, Kuroda S, Iwako H, Okimoto S, Kimura T, et al. Hepatectomy after down-staging of hepatocellular carcinoma with portal vein tumor thrombus using chemoradiotherapy: a retrospective cohort study. Int J Surg. 2017:44:223-8.

17. Nouso K, Miyahara K, Uchida D, Kuwaki K, Izumi N, Omata M, et al. Effect of hepatic arterial infusion chemotherapy of 5-fluorouracil and cisplatin for advanced hepatocellular carcinoma in the Nationwide Survey of Primary Liver Cancer in Japan. Br J Cancer. 2013;109(7):1904-7.

18. Song DS, Song MJ, Bae SH, Chung WJ, Jang JY, Kim YS, et al. A comparative study between sorafenib and hepatic arterial infusion chemotherapy for advanced hepatocellular carcinoma with portal vein tumor thrombosis. J Gastroenterol. 2015:50(4):445-54.

19. Torzilli G, Belghiti J, Kokudo N, Takayama T, Capussotti L, Nuzzo G, et al. A snapshot of the effective indications and results of surgery for hepatocellular carcinoma in tertiary referral centers: is it adherent to the EASL/AASLD recommendations?: an observational study of the HCC EastWest study group. Ann Surg. 2013;257(5):929-37.

20. Glantzounis GK, Paliouras A, Stylianidi MC, Milionis H, Tzimas P, Roukos D, et al. The role of liver resection in the management of intermediate and advanced stage hepatocellular carcinoma. A systematic review. Eur J Surg Oncol. 2018:44(2):195-208.

21. Kokudo T, Hasegawa K, Matsuyama Y, Takayama T, Izumi N, Kadoya M, et al. Survival benefit of liver resection for hepatocellular carcinoma associated with portal vein invasion. J Hepatol. 2016;65(5):938-43.

22. Poon RT, Fan $\mathrm{ST}, \mathrm{Ng} \mathrm{IO}$, Wong J. Prognosis after hepatic resection for stage IVA hepatocellular carcinoma: a need for reclassification. Ann Surg. 2003; 237(3):376-83.

23. Lau WY, Lai EC. Salvage surgery following downstaging of unresectable hepatocellular carcinoma--a strategy to increase resectability. Ann Surg Oncol. 2007;14(12):3301-9.

24. Chang WT, Kao WY, Chau GY, Su CW, Lei HJ, Wu JC, et al. Hepatic resection can provide long-term survival of patients with non-early-stage hepatocellular carcinoma: extending the indication for resection? Surgery. 2012:152(5):809-20.

25. Lee HS, Choi GH, Choi JS, Kim KS, Han KH, Seong J, et al. Surgical resection after down-staging of locally advanced hepatocellular carcinoma by localized concurrent chemoradiotherapy. Ann Surg Oncol. 2014;21(11):3646-53.

26. Chong JU, Choi GH, Han DH, Kim KS, Seong J, Han KH, et al. Downstaging with localized concurrent chemoradiotherapy can identify optimal surgical candidates in hepatocellular carcinoma with portal vein tumor thrombus. Ann Surg Oncol. 2018:25(11):3308-15.

27. Tabrizian P, Jibara G, Shrager B, Schwartz M, Roayaie S. Recurrence of hepatocellular cancer after resection: patterns, treatments, and prognosis. Ann Surg. 2015;261(5):947-55.

28. Shah SA, Cleary SP, Wei AC, Yang I, Taylor BR, Hemming AW, et al. Recurrence after liver resection for hepatocellular carcinoma: risk factors, treatment, and outcomes. Surgery. 2007;141(3):330-9.

29. Uka K, Aikata H, Takaki S, Shirakawa H, Jeong SC, Yamashina K, et al. Clinical features and prognosis of patients with extrahepatic metastases from hepatocellular carcinoma. World J Gastroenterol. 2007;13(3):414-20.

30. Jung SM, Jang JW, You CR, Yoo SH, Kwon JH, Bae SH, et al. Role of intrahepatic tumor control in the prognosis of patients with hepatocellular carcinoma and extrahepatic metastases. J Gastroenterol Hepatol. 2012;27(4): 684-9.

31. Yamasaki T, Kimura T, Kurokawa F, Aoyama K, Ishikawa T, Tajima K, et al. Prognostic factors in patients with advanced hepatocellular carcinoma receiving hepatic arterial infusion chemotherapy. J Gastroenterol. 2005;40(1): $70-8$

\section{Publisher's Note}

Springer Nature remains neutral with regard to jurisdictional claims in published maps and institutional affiliations.

Ready to submit your research? Choose BMC and benefit from

- fast, convenient online submission

- thorough peer review by experienced researchers in your field

- rapid publication on acceptance

- support for research data, including large and complex data types

- gold Open Access which fosters wider collaboration and increased citations

- maximum visibility for your research: over $100 \mathrm{M}$ website views per year

At BMC, research is always in progress.

Learn more biomedcentral.com/submissions 